\title{
Analysis on Jingdong's Offbeat Marketing Strategies
}

\author{
Zhenjian Jiang,Fengjuan Dong and Yixuan Tang \\ School of Business ,Shandong Jianzhu University,Jinan, China, dongfengjuanwin@126.com
}

\begin{abstract}
Jingdong, a famous E-mall for online shopping in China, has grown rapidly since its establishment. It has been regarded as a miracle in Chinese e-tailing field for a long time and now can equal some big enterprises such as Suning, Dangdang and Taobao. The reason why Jingdong achieves such a great achievement in a short period of time mainly relies on its offbeat marketing strategies in the era of Internet. This article is summarizing Jingdong's recent offbeat marketing actions. I hope this article could provide valuable reference for electronic business companies in choosing suitable marketing strategies.
\end{abstract}

Keywords-Jingdong,Marketing Strategies; Innovation

In constant innovation, Gome can dominate the national market in a short period of 22 years. But now the fast developing mall named Jingdong,constantly impacts Gome and Suning(the biggest two tailers who supply household appliances) by overthrowing the traditional business modes and adopting new skills of e-tailing.

In 2011, the trade of e-shopping market of China has reached 773.56 billion RMB and it's predicted that the amount will up to 1184 billion RMB in 2012. The market share of Jingdong(with 44.46 million consumers, only next to Taobao, a famous website for online shopping ) accounted for 36.8 percent of the total share of Chinese independent B2C websites in 2011.Its fast advancement is amazing, but what special strategies have they adopted to achieve such a big success in just 7 years?

The mall's over $200 \%$ growing speed has shocked the whole world with sales from 4 billion RMB in 2009 to 10 billion RMB in 2010, and the sales reached 21 billion RMB in 2011. Jingdong never lacks ambitions, and Liu Qiangdong, the CEO, declares that in the year of 2012 they will get to the target of 50 billion RMB (net sales). If the e-tailing field is a horse race game in the past decade, it has entered the fiercely competitive knock-out phase in 2011."The earth just needs one store"is Jingdong's inner slogan and they are working hard on becoming a comprehensive e-tailing website with competitiveness.

The facts tell us, to subvert the power of the incumbent often comes from destructive innovations, which is precisely the neglect on the new technologies, new models and new competitors of the incumbent in an absolutely dominant position. Depending on new ideas, which nowadays have been a key for enterprises to stand out, Jingdong catches up with other fellows beyond all their expectations.

\section{Jingdong Mall Is Breaking into Book Market by Competing with Dangdang}

On December 8th, just after Dangdang was listed, Liu Qiangdong declared that the books in his mall would be $20 \%$ off than any other's. The promotion directly enraged Dangdang, who decided to shoulder with all presses to drive Jingdong out of the game. And the price war broke out since then. This time, Liu still kept his strong attitude, saying that if Dangdang did not give up, Jingdong would keep the price low. The competition in e-business has begun earlier than our expectations.

Jingdong was in a heavy battle with Dangdang when Dandang was just listed, and it did an excellent marketing by giving no more than some discounts of books. Review the mall's history, from the time when their books were online to the time when the enterprise was listed, Jingdong has really done a good job with the help of their series of marketing strategies.

Zhang Fan, a researcher of intellectual property from China University of Political Science and Law, says that from the view of marketing, this price battle is undoubtedly successful to Jingdong for the fact that as a new e-saler of books, Jingdong doesn't appeal for too much attention at first.Because of the costly but effective price battle, such vast number of consumers has noticed the new business of Jingdong that it becomes the place they buy books online. Jingdong has caught more eyes in the battle than Dangdang.

The price war against Dangdang is just their announcement that they also sell books, and the discounts will be regarded as the cost of promotion. Before that, Jingdong's another slogan, “All things are cheap here", tells people to go on www.360buy.com to purchase.

\section{Tomato Scandal, a Love Story Happens in Jingdong.}

On the night of July 15th 2012, the CEO, Liu Qiangdong and his female staff posted a photo of small tomatoes on their microblogs almost at the same time, which caused Netizens to discuss their relationship for the picture was observed as the same one. Though deleting the picture in a hurry, still did they give rise to the gossip about a love story. Even such fellowsalers as Taobao and Dangdang also joined in the discussion.

Next morning, Liu lamented on his microblogging,"Gossip , gossip, there are gossips everywhere on the micro-blog!" Later on ,he showed his absolute innocence.

In my opinion, however, Liu's blog was not just for entertainment, and the popular Tomato Scandal was not just about the CEO and the female superintendent either. There's no doubt that it's Liu's guerrilla-like sensationalization in business.

In the morning of July 17th, Liu Qiangdong sent a new micro-message, "I often drink tomato beverage, it's good for beautification and losing weight. But why has the Food 
Department not yet to put the tomato seeds on the shelf?" and hyperlink a website where the tomato beverage was sold in Jingdong at the same time. Not too long after that, their official micro-blog announced to ceremoniously introduce a new channel about fresh food and it was tomato that was primarily recommended. Liu reshared the blog and said "Good job, Jingdong! People who sees this message but doesn't reshare it will have no tomatoes to eat!" An insider disclosed that this incident could not be excluded from the possibility of making use of event marketing.

Jingdong's tomato has become popular on the Internet and lots of sellers seize the chance to promote the sales of tomato. Stores in Taobao take advantage of the event to introduce the seeds which is same as that of Tomato Scandal. And Dangdang, the old opponent, is the most active in pushing special promotions in the name of the event like "balcony love story" and "the secret of balcony tomato" in order to sell their books, shoes and electronics.

\section{Cooperating with the Media, Jingdong Shows up in the Screen.}

\subsection{With the TV Sets}

"Men Group", a hot TV soap opera last year, really help Jingdong a lot to be known nationwide for the players" fashionable clothes are coming from their mall. Except for the humorous dialogues and excellent acting, the actor's scarf and waistcoat immediately become star productions in e-shops, and put on sale on www.360buy.com only. Over the past several years, the mall has been making their fortune in a low tone and this is their first time to show up in TV screen where they have successfully caught a big business chance. Though their ads in "Men Group" caused public disputes, the large amount of sales since the drama is broadcasted proves that it's a typical case of marketing in entertainment circle.

There are several ways usually used in TV sets for enterprises to advertise, but Jingdong doesn't only implant its brand into "Men Group" but also tells the television audience to consume in their mall just like what the fashionable roles do in the soap opera. As the plots develop, an idea that go to www.360buy.com to buy what you want might occur to the audience and it's more effective than repeatedly showing them their brand mark.

Besides advertising in the drama, Jingdong also puts advertisements in the five channels where "Men Group" are broadcasted and the actor, Sun Honglei's words in the ad push a trend all over China: "Don't want to be out? I'll leave you a word: fashion. It's good for you that all fashionable clothes in 'Men Group' can be found in Jingdong mall." Sun's acting in the ad makes it and the drama matched well and impresses the audience deeply. During the broadcasting period, some wellplaced promoting projects are also introduced along with the TV show.

\subsection{With the Movies}

As movie industry develops fast in China, the film media also matures gradually and cinema followers have been the core and steady consumers in society. Jingdong chooses these people as their target buyers due to their sensitivity to fashion. They want to take advantage of the media platform to jump into a higher level and decide to cooperate with the biggest media operator-the CCTV Movie Media, which possesses the largest fashionable consumptive group that Jingdong rightly selects.

In the year of 2011, the number of people who see movies has reached 0.38 billion $\mathrm{RMB}$, and the steady crowd numbers 30 million RMB. It means that these people go to cinema once or twice every month. Jingdong shows ads before upcoming movies with the help of its cooperator to set up their image among viewers.

In addition, on the Valentine's Day, according to the activity named "SMART is only very smart in Jingdong", the CCTV Movie Media makes a project both in screen and in cinema hall for propaganda. The SMART is a sub production of Mercedes - Benz car which is popular among the youth who follow the fashion trend and adore creative life-style. Besides showing their brand in screen, they also drive the car model into the cinema and display it in a special and novel way. It attracts passengers to stop and stare and the advertisers therefore have a face-to-face communication with consumers. Undoubtedly Jingdong's marketing strategy of advertising by media is successful because the whole 300 cars are sold out in 89 minutes. Since then, the mall gets rid of the old image that only sells appliance and walks into their target group rightly. Moreover, it also shows us that there are big business chances involved in the media area.

\section{Continuously Exposed, Jingdong Is Unwilling to Be Neglected.}

On October $30^{\text {th }} 2012$, Jingdong mall pushed out a new business that customers who accumulate enough buying points can get some goods of equal value. But the next day, news from network exposed that there was a loophole in the barter system so that buyers can change and purchase anything unlimitedly, which was responded by Jindong's official after verification that it's just a mistake caused by system bug when the business was introducing. There's hearsay that because of the mistake, Jingdong suffered from a serious loss of over 0.2 billion RMB. However, the mall itself denied the rumor, declaring they've repaired the barter system at the first time and it operates well now. If the news is true, it means that such an incident doesn't bring any loss for Jingdong but helps to attract more attention of the public. So I wonder it's Liu's another strategy to promote their barter business.

On the other hand, Jingdong cooperates with Ku6, a video website, to launch talent shows in over 200 campuses located in ten cities to propagate their sites because the campus are inclined to the cheap and convenient online-shopping and therefore dominates the mall's target customer groups. They say the winners will get some scholarships and opportunities to act in their plays which will be shown on the Internet. There's no wonder that Jingdong takes advantage of these incentives which make contests both recreational and public. Conveying 
Jingdong's spirit and information to their target group unconsciously, such accurate marketing strategies attract campuses to consume in the mall and also raise its social exposure to be well known.

\section{Conclusions}

As a consumer who always compares among these online stores and chooses the best at last, I have an aggressive impression on Jingdong mall, whose series of different strategies are more or less an imitation of Mao Zedong's tactics adopted in the guerrilla warfare when the enemy was more powerful than us. No wonder some people say, the developing way of Jingdong is wild and unruly.

Jingdong's innovation in marketing makes www. 360buy.com deep into people's heart and there's no doubt that it did get a large number of consumers' addiction to purchasing things on the website. But how to find a balance point between accelerating its development and strengthening technological management of service quality? How to implant the brand deep into consumers' mind while keeping its good image? And how to get more profit from its rapidly increasing scale? Jingdong probably still has a long way to go.

\section{References}

[1] Wang Shanshan.The Rushingly Developed Jingdong.Jinshang College, 2011(12):85-87.

[2] Fan Xiaodong.How Is Jingdong Listed in 2012?CHINA INTERNET WEEK, 2012(2).

[3] Wu Qian.The B2C Price War : Jingdong Take Advantage of Dangdang. CHINA INTERNET WEEK, 2011(1).

[4] Gu Liening.Rush for 50 billion!Jingdong Challenges Selling Appliances Online. Shanghai Economy Monthly, 2012(3). 